\title{
Endoscopy-assisted early correction of single-suture metopic craniosynostosis: a 19-year experience
}

\author{
David F. Jimenez, MD, ${ }^{1}$ Michael J. McGinity, MD, ${ }^{1}$ and Constance M. Barone, MD² \\ 'Department of Neurosurgery, University of Texas Health San Antonio; and ${ }^{2}$ Cosmetic Surgery Center, San Antonio, Texas
}

OBJECTIVE The objective of this study was to present the authors' 19-year experience treating metopic craniosynostosis by using an endoscopy-assisted technique and postoperative cranial orthotic therapy. The authors also aimed to provide a comprehensive, comparative statistical analysis of minimally invasive surgery (MIS) versus open surgery in reports previously published in the literature (through 2014) regarding only patients with metopic synostosis.

METHODS A total of 141 patients with single-suture metopic nonsyndromic craniosynostosis sutures were treated between 1998 and 2017 by endoscopically resecting the synostosed bone followed by postoperative custom cranial orthosis use. All data used in the case series were collected prospectively and stored in a secure database. A comprehensive literature review was performed that included all previous case series reporting common surgical performance measures. A statistical comparison of traditional open methods versus MIS techniques was performed with regard to age, length of hospital stay (LOS), surgical time, estimated blood loss (EBL), and transfusion rate.

RESULTS The mean age at the time of surgery in the current series was 4.1 months. The mean EBL was $33 \mathrm{ml}$ (range 5-250 ml). One patient underwent an intraoperative blood transfusion and 5 underwent postoperative blood transfusion for a total transfusion rate of $4.3 \%$. The mean operating time was 56 minutes. Ninety-eight percent of patients were discharged on the 1 st postoperative day. The median size of the removed synostosed bone was $0.6 \mathrm{~cm} \times 10 \mathrm{~cm}$. The primary goal of achieving correction of the forehead deformity was obtained in $94 \%$ of the patients. One hundred eight patients presented with hypotelorism (76.6\%). Those with a minimum 1-year follow-up achieved $99 \%$ correction ( $n=$ 97). Six patients younger than 1 year had not achieved correction at the time of follow-up (6\%). There were no intra- or postoperative deaths. One patient had a temporary contact dermatitis to the helmet materials and 2 patients developed pseudomeningoceles, which were successfully treated with a lumbar drain and/or spinal tap. No patient required nor underwent a second surgical procedure. Regarding the previously published literature through 2014, the reported EBL in patients who underwent MIS versus traditional open methods was $54.7 \mathrm{ml}$ versus $224 \mathrm{ml}$, respectively. The reported average age for patients undergoing MIS versus traditional open methods was 3.8 months versus 11.5 months. The average LOS for patients undergoing MIS versus traditional open methods was 1.7 days versus 3.7 days. The average reported surgical time for those undergoing MIS versus traditional open methods was 66.7 minutes versus 223.7 minutes. The transfusion rate for patients undergoing MIS versus traditional open methods was $22 \%$ versus $77 \%$. All of the above differences demonstrated statistical significance.

CONCLUSIONS The authors' team has safely and effectively performed 141 metopic craniosynostosis corrections over the past 19 years, with excellent outcomes. Literature review comparing metrics such as LOS, EBL, operating time, and transfusion rate demonstrates a statistically significant improvement in all commonly reported measurements. MIS techniques are safe and effective and should be offered to parents and patients as an option at craniofacial centers treating this condition.

https://thejns.org/doi/abs/10.3171/2018.6.PEDS1749

KEYWORDS metopic; craniosynostosis; endoscopy; trigonocephaly; craniofacial

ABBREVIATIONS EBL = estimated blood loss; FOA = fronto-orbital advancement; IFZD = interfrontozygomatic distance; IPD = interpupillary distance; $L O S=$ length of hospital stay; MIS = minimally invasive surgery.

SUBMITTED January 25, 2017. ACCEPTED June 14, 2018.

INCLUDE WHEN CITING Published online September 28, 2018; DOI: 10.3171/2018.6.PEDS1749. 
$\mathrm{M}$ ETOPIC craniosynostosis, a consequence of premature closure of the metopic suture, results in the deformity of trigonocephaly. Patients present with the classic triangular-shaped forehead due to severe lateral growth restriction of the two frontal bones. A midline anterior calvarial ridge on the forehead is seen over the synostosed suture. Hypotelorism results from deficient lateral movement of the orbits and anterior skull base. Overall intracranial frontal volume is often reduced, requiring early operative intervention to allow normal anatomical and physiological growth of the brain; as such, treatment is not only for cosmetic reasons. Metopic synostosis has been linked to neurodevelopmental delay in a number of related conditions and syndromes. ${ }^{40}$

Treating patients with metopic craniosynostosis is a challenging task for the neurosurgeon and craniofacial plastic surgeon for a number of reasons. Initial dramatic deformity correction achieved using traditional remodeling techniques can give immediate, great results. Unfortunately, the correction frequently regresses ${ }^{41}$ or often leaves the child with large scars and visible postsurgical deformities, such as turricephaly. Although involvement of multidisciplinary teams has been reported to decrease the major complication rate to an acceptable level, ${ }^{5}$ undergoing major surgery with long operating times as well as long exposure to anesthetic agents, elevated blood loss, and large-volume blood transfusions places tremendous physiological strain on the child at an early age. The development of newer, minimally invasive techniques has made the procedure safer while providing outstanding deformity correction. ${ }^{20}$ In addition, less invasive corrections have been associated with a decrease in the cost of performing these operations. ${ }^{20} \mathrm{~A}$ criticism of suturectomy has been a lack of hypoteloric correction. However, endoscopic suturectomy has been demonstrated to be equivalent to open repairs in correcting hypotelorism. ${ }^{31}$ Endoscopy-assisted strip craniectomy of the metopic suture was first performed by the authors in 1998, and they have been performing the procedure for the past 19 years with excellent results.

\section{Methods}

The authors have collected a detailed, prospective pre-, intra-, and postoperative database over the past 19 years. The database was searched and included all patients undergoing correction of isolated nonsyndromic metopic craniosynostosis. Data were collected regarding sex, age, weight, operative duration, length of hospital stay (LOS), estimated blood loss (EBL), transfusion requirements, and size of resected synostosed bone as well as any associated complications. Cranial anthropometric measurements, including interpupillary distance (IPD) and interfrontozygomatic distance (IFZD), were also recorded and analyzed. In addition, an extensive literature review was performed of all previously published series reporting surgical performance measures. A statistical analysis was performed comparing traditional open methods against minimally invasive surgery (MIS) techniques. Institutional review board approval was obtained. Hypotelorism is a craniofacial condition associated with premature synostosis of the metopic suture, which does not allow for normal lateral movement of the forehead, orbits, and anterior base of the skull. Severity of hypotelorism increases with earlier suture synostosis.

We analyzed all of our patients by measuring standard facial photographs (anteroposterior views) and measuring their IPD and IFZD. A ratio between these two measurements was obtained by dividing IPD by IFZD and multiplying by $100($ Teloric Ratio = IPD/IFZD $\times 100)$. This ratio measures lateral orbital movement and accounts for overall cranial growth. Photographs of 100 normal males and females were measured using this ratio. Photographs of 20 hypoteloric and 20 hyperteloric patients were measured using the same ratio. It was found that a normal ratio ranges between 40 and 55. Hypotelorism is defined as a ratio less than 40 and hypertelorism as a ratio greater than 55 .

\section{Study Population}

Between 1998 and 2017, a total of 141 consecutive patients with metopic single-suture nonsyndromic craniosynostosis were treated with endoscopy-assisted craniectomy of the involved metopic suture. One hundred seven patients were male $(75.9 \%)$ and $34(24.1 \%)$ were female. The mean age at time of surgery was 4.1 months (median 3.9 months, range $0.82-12.64$ months). The mean weight of the patients was $6.4 \mathrm{~kg}$ (median $6.5 \mathrm{~kg}$, range 3.5-10.7 $\mathrm{kg}$ ). The only preoperative serum value obtained was a single heel-stick, spun hematocrit level following anesthesia induction. The median length and width of the removed bone strip were $10 \mathrm{~cm}$ and $0.6 \mathrm{~cm}$, respectively, and the strip extended from the anterior fontanelle to the nasofrontal suture. Although our overall group of patients with craniosynostosis included 12 with multiple-suture synostosis that involved the metopic suture, we decided to exclude that group from the present study and only report on patients with nonsyndromic, single-suture, metopic craniosynostosis to keep the cohort with a similar denominator.

\section{Anesthesia Procedure}

After preoperative evaluation, the patient is taken to a heated operating suite and placed onto the operating table. The patient is closely monitored with electrocardiograms, noninvasive blood pressure cuff, and 2 pulse oximeters. Anesthesia induction is accomplished with inhaled sevoflurane with oxygen and nitrous oxide. A preoperative heel-stick hematocrit level is obtained at the time of intravenous cannulation. Peripheral access is achieved using 1 or 2 intravenous lines and no arterial or central venous catheters. Typically, further muscle relaxation is not required due to the short surgical duration. Intubation is performed and the endotracheal tube is secured following auscultation for equal bilateral breath sounds. Antibiotics, typically cefazolin at $40-60 \mathrm{mg} / \mathrm{kg}$, are administered intravenously. Analgesia is achieved with $1-2 \mu \mathrm{g} / \mathrm{kg}$ of intravenous fentanyl and rectal acetaminophen (10-15 mg/ $\mathrm{kg}$ ). Warming blankets, heat lamps, warmed intravenous fluids, and a heated operating suite are used to maintain core body temperature throughout the operation. Anesthe- 


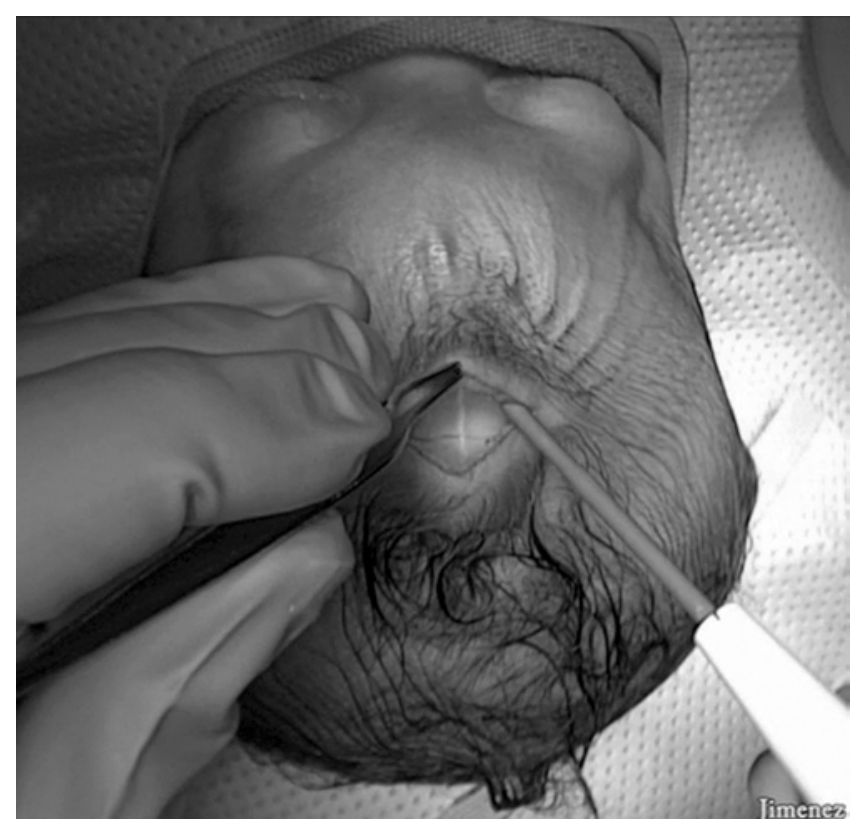

FIG. 1. Intraoperative photograph showing the surgeon developing the anterior subgaleal plane by using monopolar electrocautery and a rhinoplasty lighted retractor. Care is taken to leave the pericranium intact.

sia is maintained with inhaled sevoflurane and oxygen and intravenous fentanyl as needed. All patients have a precordial Doppler placed on the anterior chest wall to monitor for venous air emboli. A second hematocrit is obtained at the conclusion of surgery to assess and estimate blood loss. Anesthesia is discontinued and the patient is extubated once meeting extubation criteria. The patient is then transported to the postoperative care unit with supplemental oxygen and standard monitors.

\section{Surgical Procedure}

The patient is placed supine with the head on a pediatric cerebellar headrest. Corneal protection is obtained with ophthalmic lubricant ointment and corneal protective shields. The forehead, eyes, nose, and cheeks are prepared with the povidone-iodine scrub and paint. Sterile drapes are used to drape the aforementioned prepared areas. The area for skin incision is selected behind the hairline and in front of the anterior fontanelle. The amount of the bone removal is approximately $6 \mathrm{~mm}$ wide and extends from the anterior fontanelle to the nasion. The scalp is directly incised with a monopolar needle tip unit set at $15 \mathrm{~W}$ on cut mode. Once the epidermis is incised, the working mode is changed to coagulation set at $20 \mathrm{~W}$. The incision length is between 2.5 and $3 \mathrm{~cm}$ and extended below the galea but above the pericranium (Fig. 1); stripping or removing the pericranium will lead to unnecessary blood loss. The subgaleal tissue dissection is extended posteriorly to the anterior fontanelle and anteriorly to the nasofrontal suture with the aid of a lighted Aufricht Rhinoplasty Retractor (Fig. 2). A burr hole is made with a drill equipped with a 7-mm pediatric craniotome perforator (ACRA-CUT) and located directly over the stenosed

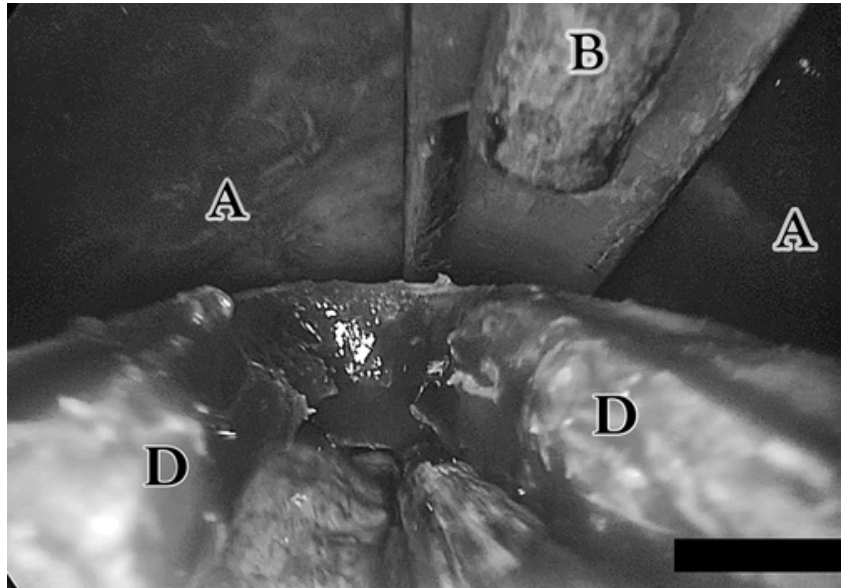

FIG. 2. Endoscopic view of the scalp (A) being retracted with a rhinoplasty lighted retractor $(B)$ and the edges of the cauterized osteotomy (D).

metopic suture at the incision site. A 4-mm Kerrison rongeur is used to longitudinally enlarge the burr hole to the anterior fontanelle. Attention is focused anteriorly, where a No. 1 Penfield dissector is used to free the dura mater from the overlying bone halfway down the forehead. The epidural area is inspected with a $30^{\circ}$ endoscope, along with an insulated 7-Fr Jackson suction device, which are used to further develop the epidural plane down to the nasofrontal suture.

Almost always, bleeding will be seen coming from bridging veins that extend from the sagittal sinus and dura to the stenosed suture and frontal bone. These are coagulated with an endoscopic bipolar (Karl Storz, Endoscopy-America, Inc.) (Fig. 3). If bleeding can't be readily stopped, the table can be lowered and the head of the bed elevated, while carefully listening to the precordial Doppler for venous air emboli. This maneuver will ensure that the bleeding is fully stopped and that the veins and dura are coagulated under direct visualization. Generous amounts of Surgiflo (Johnson \& Johnson) can be used to ensure further coagulation. Once the dura has been fully separated from the cranial bone and bleeding from the dural veins is controlled, a wedge of bone $(6 \mathrm{~mm} \times 3-4 \mathrm{~cm})$ can be cut using Mayo scissors or bone-cutting scissors (Karl Storz).

The rest of the osteotomy is made in a piecemeal fashion using bone-cutting rongeurs (Acromed) (Fig. 4). Care must be taken that the osteotomy is continued all the way down to the nasofrontal sublevel (Fig. 5) in order to ensure full release of the frontal bones. A small osteotome can be used to fully split the nasofrontal suture. A suction electrocautery unit (Valley Lab), set at $60 \mathrm{~W}$ in coagulation mode, is used to fully cauterize the diploë all along the osteotomy (Fig. 6). The Stryker electric bone rasper is then used to smooth out the edges of the osteotomy and remove any sharp pieces of remaining bone. This is particularly important for patients with significant trigonocephaly and prominent metopic ridges. In these patients the sharp edge of the osteotomy can cause prominence and postoperative 


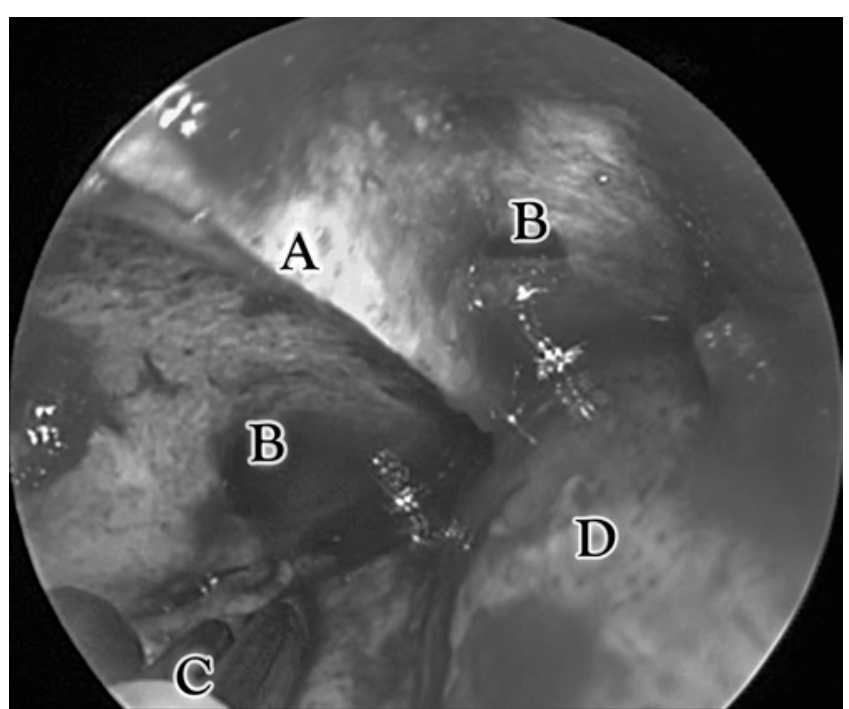

FIG. 3. Endoscopic view of epidural plane development behind the frontal bone. Halfway down the forehead, dural bridging veins are often encountered entering the cranial bone (B). These can be directly coagulated with a Storz endoscopic bipolar coagulator (C) as the dura (D) and the stenosed metopic suture (A) are visualized.

pain. Prior to skin closure, Surgiflo is left on the surgical bed, which is inspected with an endoscope to make sure that no CSF leaks are present with a Valsalva maneuver. The galea is closed with interrupted 4-0 monocryl suture (Ethicon). Bupivacaine $0.25 \%$ with epinephrine 1:200,000 is used for incision block as well as supraorbital nerve block bilaterally at a $1 \mathrm{ml} / \mathrm{kg}$ dose. Mastisol and SteriStrips are used for the dermal closure.

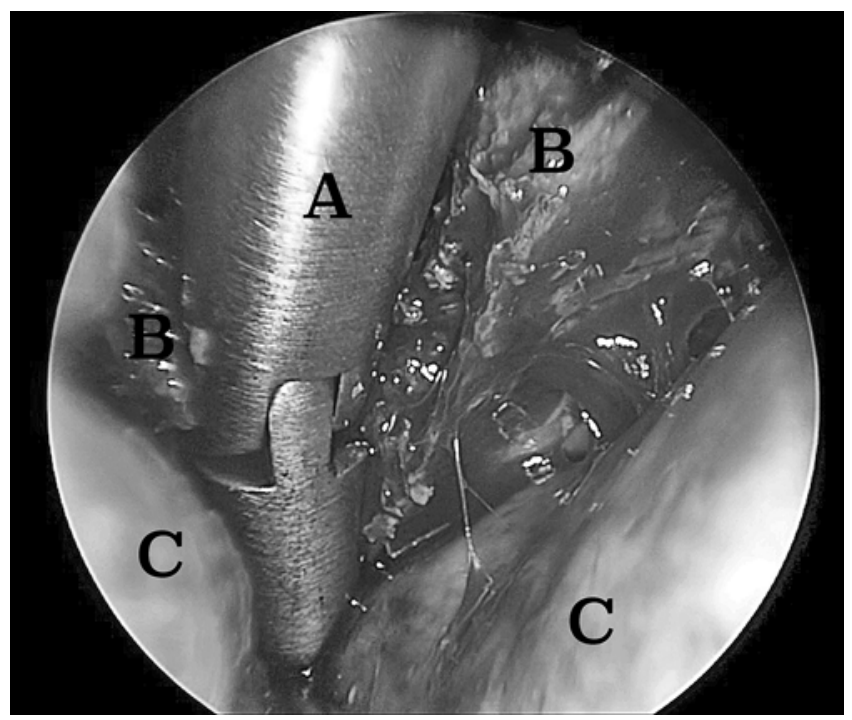

FIG. 4. Endoscopic view shows the golden tip of the bone rongeurs $(A)$ used to remove the stenosed suture in a piecemeal fashion. The frontal bone (B) and dura (C) are seen.

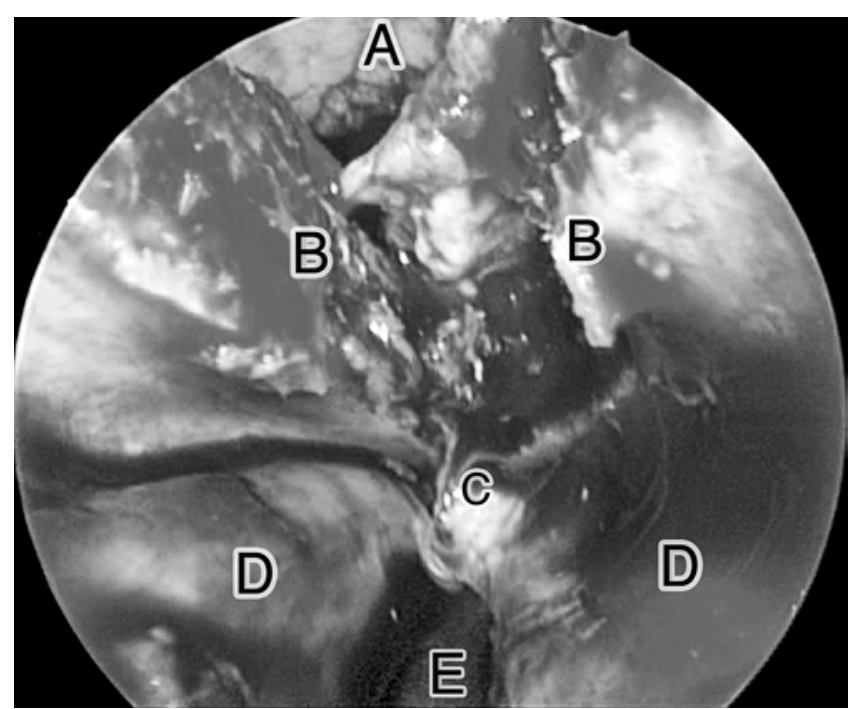

FIG. 5. The midline osteotomy has been made and the edges (B) are seen as well as the nasofrontal suture (C). The scalp (A) and dura (D) are also seen as the Frazier suction tube $(\mathrm{E})$ gently retracts the dura to show the nasofrontal suture.

\section{Postoperative Orthosis}

The use of postoperative custom cranial orthosis is critical in obtaining excellent results when resecting synostosed cranial sutures. The primary concept is to redirect brain growth and proceed with the changes to compensate for the abnormal cranial shape. The orthosis does not restrict overall growth but holds growth in the anteriorposterior direction while allowing for the forehead and temporal areas to expand and correct the trigonocephalic

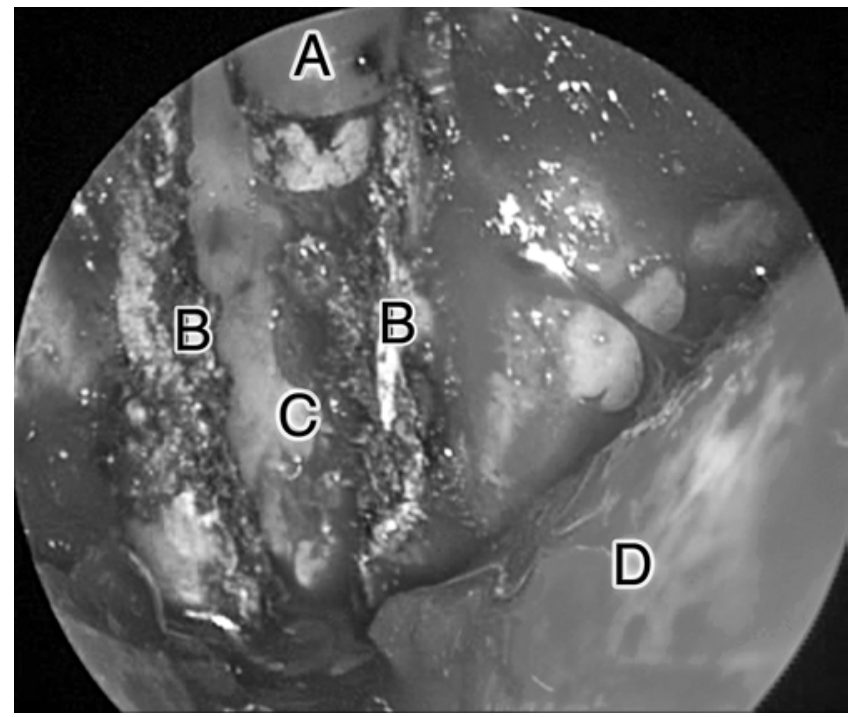

FIG. 6. After osteotomy is finished, bleeding from the bony edges is cauterized (B) using a suction electrocautery unit (A) set at $60 \mathrm{~W}$. The scalp (C) and dura (D) are seen as well. 


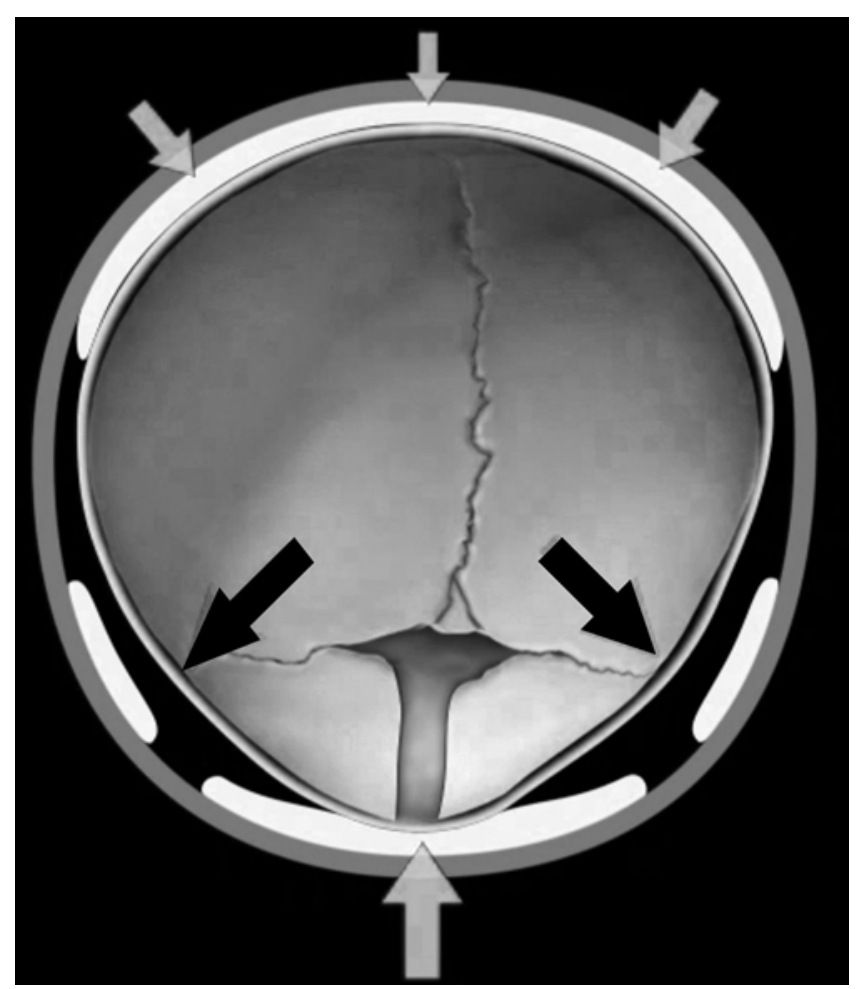

FIG. 7. Artist's diagram shows compressive forces (black arrows) being applied by a cranial orthosis to the opisthocranion, glabella, and biparietal areas while the bifrontal and temporal areas (white arrows) are allowed to expand and correct the cranial deformity.

shape (Fig. 7). Using an infrared beam STARscanner (Orthoamerica Products, Inc.), a custom-made orthosis is manufactured and delivered on postoperative day 5 . The STARscanner uses eye-safe laser data acquisition technology with immediate 3D reconstruction of the child's head. The orthoses are made with Surlyn (DuPont), which is a thermoplastic ionomer resin. It is a superb material for molding cranial helmets. The inner padding is made of an ethylene acetate lining. The patients are scanned in the neurosurgery clinic in San Antonio and the images sent to a central manufacturing center in Orlando, Florida, where the custom orthosis is constructed using a computer-assisted process. The patient begins wearing the orthosis immediately upon delivery during the first postoperative visit (postoperative day 5), and soon achieves a schedule of 23 hours per day wear. Adjustments can easily be made by adding or subtracting the inner layers to further customize the orthosis. Once correction is achieved the orthosis therapy is stopped. The orthosis is universally well received and worn by the patients throughout the treatment phase.

\section{Results}

One hundred forty-one patients underwent endoscopyassisted suturectomy for metopic craniosynostosis over a 19 -year period. One hundred seven boys underwent surgery compared to 34 girls. The median age at time of sur-
TABLE 1. Summary of patients' age, EBL, surgical time, LOS, and helmet metrics

\begin{tabular}{ll}
\hline \multicolumn{1}{c}{ Surgical Metric } & Value \\
\hline Median age (range) & $3.9 \mathrm{mos}(0.82-12.64 \mathrm{mos})$ \\
\hline Median EBL (range) & $25 \mathrm{ml}(5-250 \mathrm{ml})$ \\
\hline Median surgical time (range) & $55 \mathrm{mins}(29-113$ mins $)$ \\
\hline Median LOS (range) & 1.0 day (1-6 days) \\
\hline Complications & $\begin{array}{c}2 \text { pseudomeningoceles, 2 superficial } \\
\text { stitch abscesses, } 1 \text { wound infection }\end{array}$ \\
\hline Duration of helmet therapy & Removed at 12-18 mos of age \\
\hline Average no. of helmets & 3 \\
\hline
\end{tabular}

gery was 3.9 months (mean 4.1 months, range $0.82-12.64$ months), and the mean weight was $6.5 \mathrm{~kg}$ (median $6.5 \mathrm{~kg}$, range $3.5-10.7 \mathrm{~kg}$ ). The patients were closely followed during the first 2 years after surgery, with an average of 8 visits during this time period. The mean duration of follow-up was 6.2 years, with an SD of 2.9 years. The mean operative duration was 56 minutes (median 55 minutes, range 29-113 minutes). Ninety-eight percent of patients were hospitalized overnight and discharged on postoperative day 1 . The mean EBL was $33 \mathrm{ml}$ (median $25 \mathrm{ml}$, range 5-250 ml) (Tables 1 and 2). A total of 6 patients received a blood transfusion (1 intraoperatively, 5 postoperatively), for a $4.3 \%$ transfusion rate. Correction of trigonocephalic features takes place faster in younger patients-with those undergoing operation when younger than 3 months of age-achieving forehead normalization within 6 months. In these cases, only 1 or 2 orthoses may be required overall. Final correction takes place slowly, because the growing brain provides the correction. The midforehead area flattens under orthosis contact, whereas the forehead sides remain angulated during the first 6-9 months of treatment. Complete normalization is typically obtained by 3 years of age (Fig. 8). Because we have not removed or affected the progenitor cells of the frontal sinuses, these will begin to develop, at later years, giving the patient a normal forehead and face appearance.

Analysis of interorbital distance and orbital movement was done by measuring changes in the teloric ratio, defined as the IPD divided by the IFZD (along the same pupillary

TABLE 2. Patients' median EBL and surgical time stratified into 2-month age intervals

\begin{tabular}{cccc}
\hline \multicolumn{1}{c}{ Age } & $\begin{array}{c}\text { Median EBL } \\
(\mathrm{ml})\end{array}$ & $\begin{array}{c}\text { Median Surgical } \\
\text { Time (mins) }\end{array}$ & $\begin{array}{c}\text { No. of } \\
\text { Patients }\end{array}$ \\
\hline 0 to $<2$ mos & 20 & 53 & 13 \\
\hline 2 to $<4$ mos & 25 & 51 & 50 \\
\hline 4 to $<6$ mos & 30 & 58 & 37 \\
\hline 6 to $<8$ mos & 40 & 59 & 31 \\
\hline 8 to $<10$ mos & 25 & 56 & 8 \\
\hline$\geq 10$ mos & 10 & 64 & 2 \\
\hline
\end{tabular}



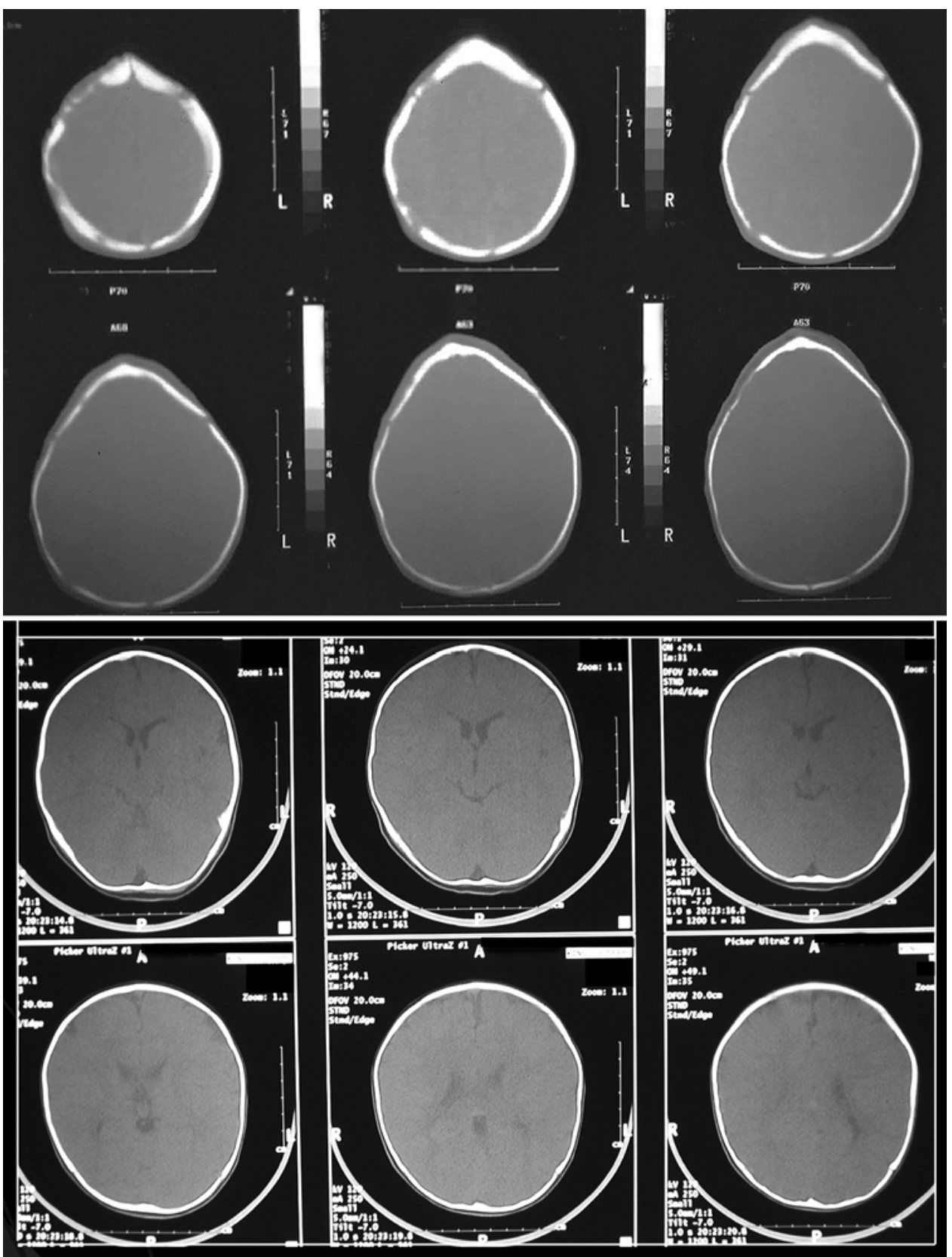

FIG. 8. Upper: Preoperative axial CT scans of a patient with fused metopic suture and trigonocephaly. Lower: Four years after surgery, axial CT scans demonstrate complete deformity correction and full reossification of the craniectomy.

plane) times 100. A ratio less than 40 constitutes hypotelorism. One hundred eight (76.6\%) of our patients presented with a ratio less than 40 (range 30.29-39.68), and 33 (23.4\%) presented with normal ratios (range 40.0-47.5). Of the 108 hypoteloric patients, 100 achieved a ratio equal to or greater than $40(93 \%)$ and 8 did not (7\%). However, 7 of these patients had short follow-up (6 weeks to 10 months) and 3 had a follow-up greater than 1 year (1.5 years).

Two patients developed midfrontal pseudomeningoceles following the surgery. In both cases a very prominent inward keel of bone was present, which led to marked thinning of the dura. In neither case was there a visible durotomy, but nonetheless CSF leaked through the dura. One patient underwent 2 spinal taps with CSF removal $(30-50 \mathrm{ml}) 2$ days apart, which led to resolution of the pseudomeningocele. The second patient had a lumbar drain placed for 5 days after the spinal taps failed to resolve the problem. The pseudomeningocele resolved with the drain and neither patient required an operation to correct the problem. Early in the series the suturectomy was larger (approximately $2 \mathrm{~cm}$ ), and 7 of the patients required close long-term follow-up of the osteotomy defect. Reos- 


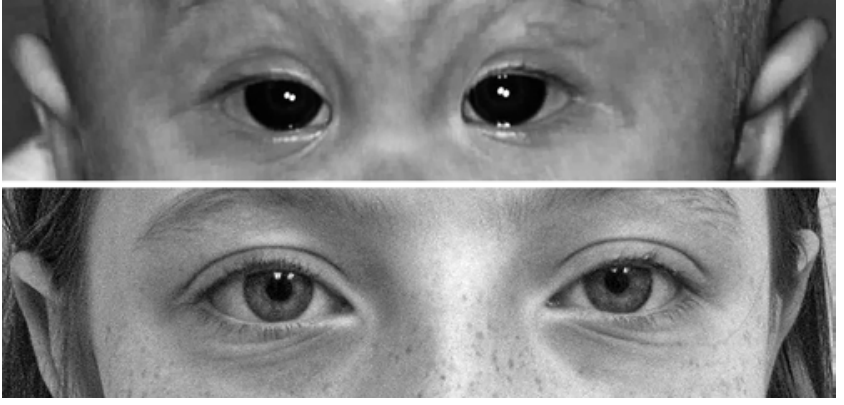

FIG. 9. Upper: Six-week-old girl with significant hypotelorism and trigonocephaly (teloric ratio: 33.4). Lower: Eleven years after endoscopic surgery, image shows complete correction of hypotelorism and persistent craniofacial normalization (teloric ratio: 50.3).

sification was delayed and ultimately closed in all patients but 2 , who were left with small bony defects that did not require a cranioplasty. One patient $(0.7 \%)$ developed a surgical site infection that required surgical wound debridement and washout.

Correction of the trigonocephalic head shape is a slow process because it requires brain growth to achieve normalization. Once the synostosis is released with the craniectomy, the molding orthosis aids in the correction by maintaining the anterior-posterior (glabella to opisthocranion) distance while allowing for the frontal bones to grow forward and laterally. Care must be taken to make sure that the osteotomy and suture removal extends from the anterior fontanelle all the way down to the nasofrontal suture. Doing so will release both frontal bones at the midline and allow for lateral advancement. Such movement leads to mobilization of the orbits and thus correction of the hypotelorism and trigonocephaly. The lateral orbital movement was noted to continue as the patients became older (Fig. 9).

Rounding of the forehead also took place in a slow, albeit definitive fashion. At first, the area surrounding the osteotomy became flat due to orthotic containment. As the patient progressively aged, the brain advanced forward and laterally, creating a more round, normal forehead shape (Fig. 10A). The medially slanted forehead seen in normally developing children was also observed in our patients until they became older and a more rounded, normal forehead was obtained (Fig. 10B and C). The number of orthoses required for treating the patients varied in an inverse proportion with age. The average duration of orthotic therapy was 11.5 months and ranged between 6 months and 14 months. Children who underwent operation at 2 or less months of age required up to 3 orthoses, which were worn for up to 12 months of age. Older children required 2 orthoses in most cases. The decision as to when to stop orthotic therapy was based on when the child reached normalization. In a number of cases this occurred in as little as 3 or 4 months after the surgery. Because we do not remove or affect the frontal sinus progenitor cells, our expectation has been that the frontal sinus will grow normally, and we have seen this occur in our older patients (Fig. 11).
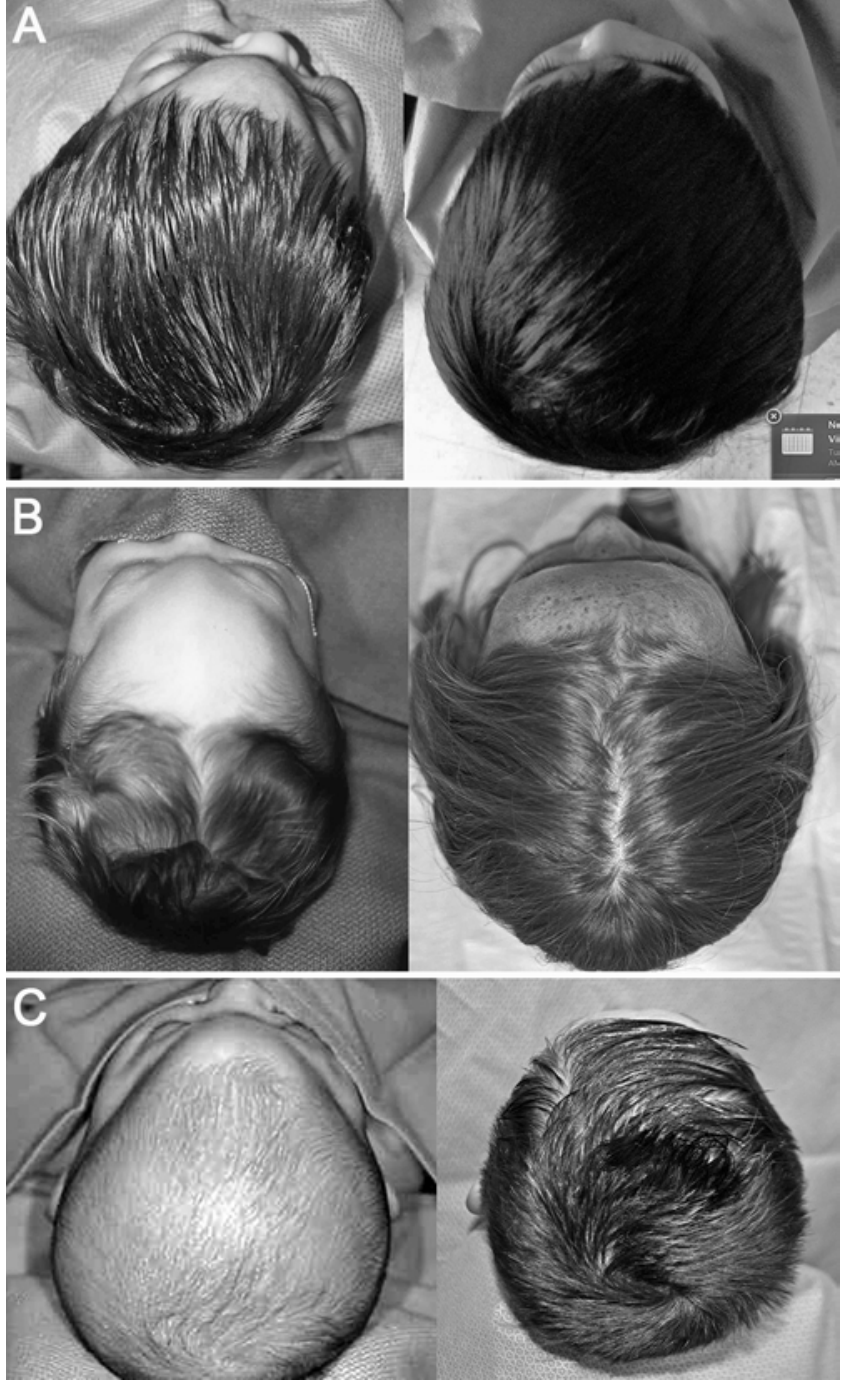

FIG. 10. A: Preoperative aerial view (left) demonstrates marked midline ridge protrusion and lateral frontal recession. Five years after surgery, image (right) shows forehead normalization. Notice lack of visible scars. B: Seven-week-old girl with metopic synostosis and trigonocephaly (left). Nine years after endoscopic surgery, image (right) shows a normal, rounded forehead. C: Preoperative photograph (left) of 5 -month-old boy with metopic synostosis. This patient presented with a subphenotype of a flattened glabella-vertex complex and significant trigonocephaly. Ten years after endoscopic surgery, photograph (right) depicts normalization of the cranial vault in all anteroposterior/lateral and cranial-caudal dimensions, with correction of forehead and cranial vault.

\section{Literature Review}

An extensive literature search was performed using PubMed, Ovid, and Google for papers published through 2014 regarding surgical treatment of metopic craniosynostosis. Number of patients, age, sex, year of publication, type of procedure, LOS, surgical time, EBL, transfusion rate, and outcomes were collected (Table 3). Series were not included if at least one of the above metrics was not reported. In addition, published series had to have isolated 


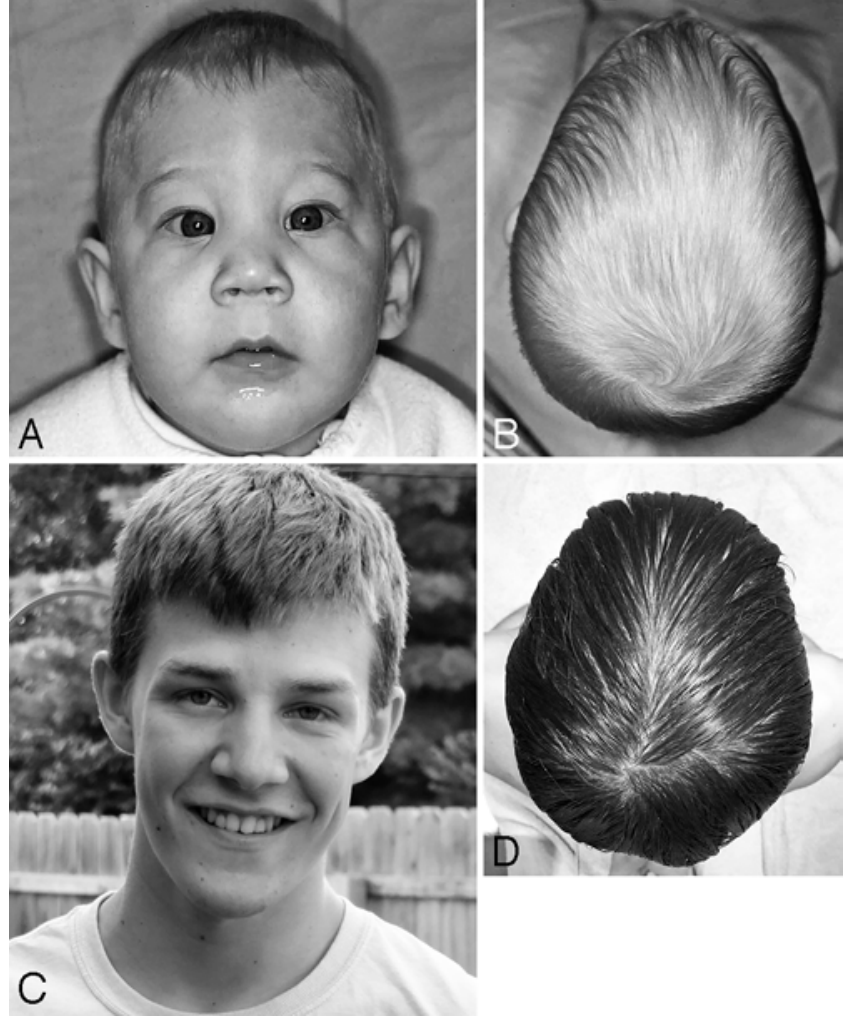

FIG. 11. A: Frontal view of 2-month-old boy who presented with metopic craniosynostosis and trigonocephaly. B: Top view of patient before undergoing endoscopic release. C: Frontal view of the same patient 18 years after undergoing the endoscopic craniectomy and release of the metopic suture followed by cranial-molding orthotic therapy. The patient presents with total forehead normalization. The development of bilateral frontal sinuses is well demonstrated. D: Top view at 18 -year follow-up.

metopic synostosis data within the paper to be included. ANOVA was performed comparing data collected from patients treated with traditional open techniques to MIS techniques. Metrics from each individual paper were weighed according to the number of subjects in the respective studies. Effect size, standard curve, and p values were obtained. Statistical significance was defined as $p<$ $0.05^{1-4,6-19,21-24,26-30,32-36,38,39,41}$

In addition, through our prior literature investigation it was noted that $70 \%$ of the patients who underwent operation were male and $30 \%$ were female. Long-term cosmetic outcomes were often discussed in a fashion that makes direct comparison between series a statistical challenge. We found complication reporting to be difficult also in making direct comparisons. The mean age at time of surgery in prior literature for open procedures $(n=1359)$ was found to be 11.5 months compared to 3.8 months for MIS ( $\mathrm{n}=$ 135) (Table 4). This age difference was found to be statistically significant $(\mathrm{p}=0.0089)$. The mean EBL in prior literature for open procedures $(\mathrm{n}=229)$ was found to be $224 \mathrm{ml}$ compared to $54.7 \mathrm{ml}$ in minimally invasive procedures $(n=116)$. This difference was found to be statistically significant $(\mathrm{p}=0.0003)$. The mean surgical time in prior literature for open procedures $(n=105)$ was found to be 223.7 minutes compared to 66.7 minutes for minimally invasive procedures $(\mathrm{n}=98)$. This difference was found to be statistically significant ( $p=0.0122$ ). The mean rate of transfusion in prior literature for open procedures $(\mathrm{n}=$ 202) was found to be 0.77 compared to 0.22 for MIS (n = 109). This difference was found to be statistically significant $(\mathrm{p}=0.0028)$. The mean LOS in prior literature for open procedures $(n=1056)$ was reported at 3.7 days compared to 1.7 days for minimally invasive procedures (n $=98$ ). This difference was found to be statistically significant $(\mathrm{p}=0.0002)$.

As described above, prior series demonstrated a statistically significant difference in all comparable variables we collected. Long-term cosmetic outcomes were too often not reported or reported in a fashion that did not allow interseries comparison. However, from a patient safety and expected cost standpoint (EBL, transfusion rate, surgical time, LOS), the reported data indicate clear superiority favoring MIS.

\section{Discussion}

As previously discussed in one of our publications, ${ }^{25}$ surgical correction for craniosynostosis began in modern times with Lannelongue (1890) and Lane (1892), who used strip craniectomies for surgical correction of these conditions. As the field of craniofacial surgery developed in earnest in the 1970s, the primary procedures of choice for correction for metopic craniosynostosis became bifrontal craniotomies, orbital bandeau remodeling, and frontoorbital advancement (FOA). Such procedures have been performed by most craniofacial centers worldwide during the last 4 decades. A review of the literature, presented herein, demonstrates these procedures to be safe and often effective. Nevertheless, it is associated with significant blood loss, blood transfusions, blood product transfusions, marked facial and/or orbital swelling, facial pain, and longer hospitalizations (4-6 days). Overall complication rates of up to $35.9 \%$ have been recently reported in well-analyzed series. ${ }^{37}$ At the time of surgery and during the early periods postoperatively the cosmetic results are excellent. Swelling and bruising typically subside within 1 or 2 weeks and the patients return to a normal state. Notwithstanding, as time goes on, the early excellent results begin to deteriorate. It is not uncommon and rather the rule that the edges of the osteotomies will become visible, as will the wires, plates, and screws used to hold the osseous constructs together. Such events have been ameliorated by the use of absorbable plates and screws; nonetheless, the "bumps and lumps" as well as osseous defects will not be affected by the use of absorbable materials. Another long-term problem seen with these procedures is the development of turricephaly. It is our belief that use of materials to stabilize and hold the bony construct in place restricts growth and displacement along the sagittal plane, leading to turricephaly.

Treating patients with metopic craniosynostosis proves to be a challenge, because the work does not finish at the end of surgery. A recent review of open surgical correction at a major center revealed great immediate results after surgery, but unfortunately found a significant decline in cosmesis over time. ${ }^{41}$ Early minimally invasive interven- 


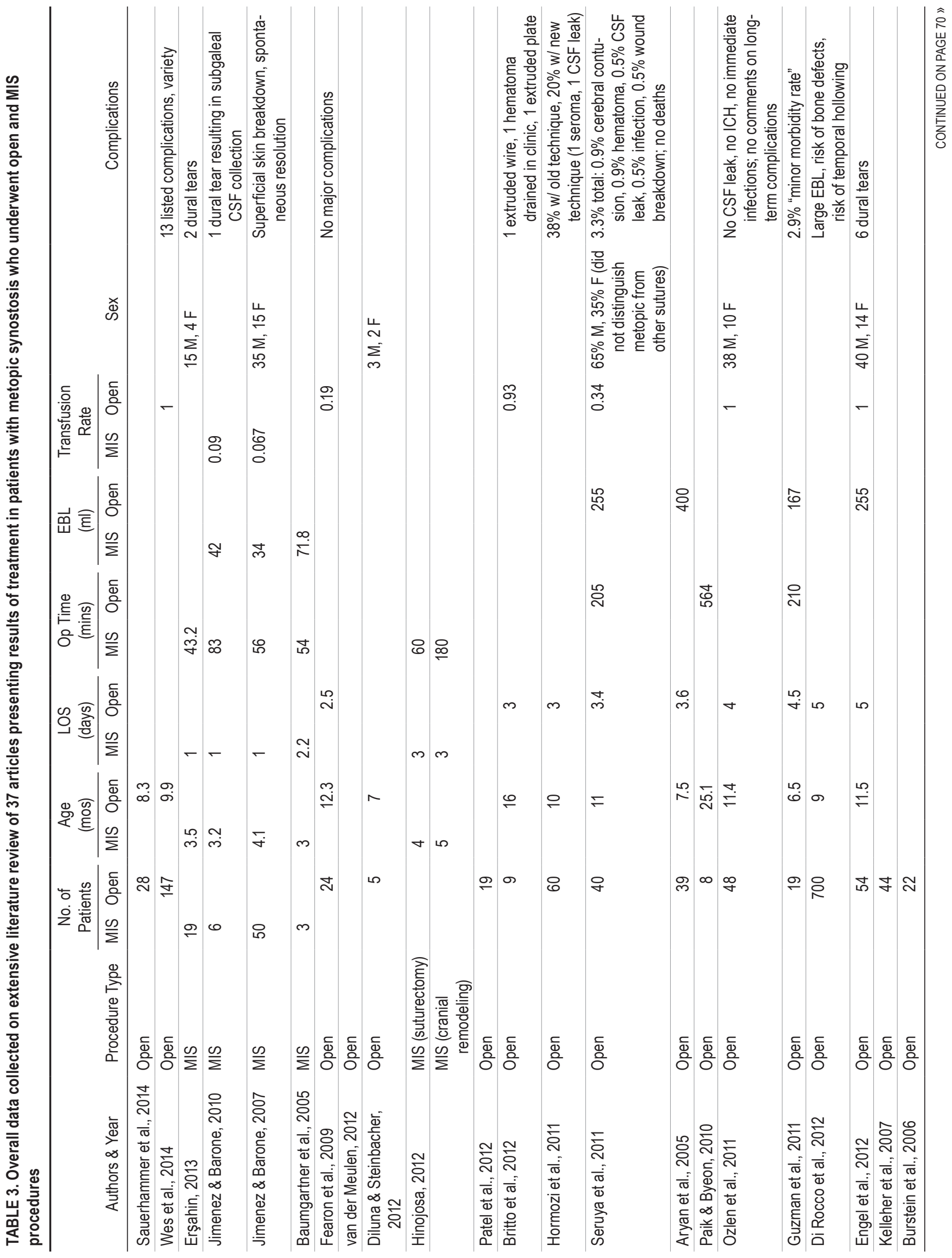




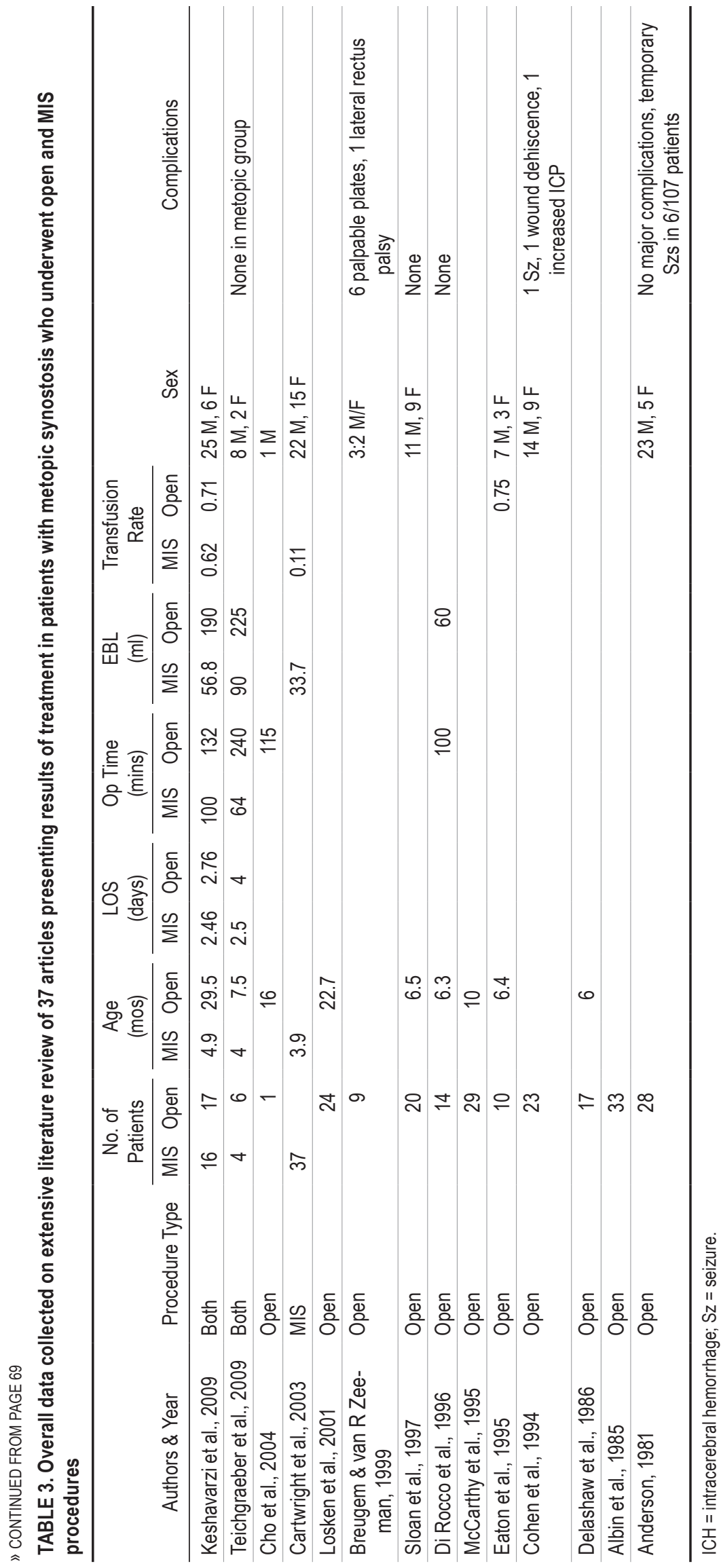


TABLE 4. Summary comparison data of open versus MIS procedures for treatment of metopic craniosynostosis

\begin{tabular}{|c|c|c|c|c|c|}
\hline Variable & Mean & Median & SD & No. of Studies & No. of Patients \\
\hline \multicolumn{6}{|l|}{ Age (mos) } \\
\hline Open & 11.54 & 9.9 & 6.36 & 23 & 1359 \\
\hline MIS & 3.8 & 3.9 & 0.64 & 7 & 135 \\
\hline Effect: -5.89 & SEM: 2.1 & $95 \%$ Cl: $-10.19,-1.6$ & $p=0.0089$ & & \\
\hline \multicolumn{6}{|l|}{ LOS (days) } \\
\hline Open & 3.68 & 3.5 & 0.84 & 12 & 1056 \\
\hline MIS & 1.69 & 1.6 & 0.77 & 6 & 98 \\
\hline Effect: -3.21 & SEM: 0.68 & $95 \% \mathrm{Cl}:-4.65,-1.76$ & $p=0.0002$ & & \\
\hline \multicolumn{6}{|l|}{ Op time (mins) } \\
\hline Open & 223.71 & 205 & 159.23 & 7 & 105 \\
\hline MIS & 66.7 & 60 & 21.02 & 6 & 98 \\
\hline Effect: -145.96 & SEM: 48.75 & $95 \%$ Cl: $-253.25,-38.67$ & $p=0.0122$ & & \\
\hline \multicolumn{6}{|l|}{$\mathrm{EBL}(\mathrm{ml})$} \\
\hline Open & 224 & 232.5 & 95.96 & 8 & 229 \\
\hline MIS & 54.72 & 49.4 & 22.69 & 6 & 116 \\
\hline Effect: -211.87 & SEM: 41.68 & $95 \%$ Cl: $-302.67,-121.07$ & $p=0.0003$ & & \\
\hline \multicolumn{6}{|l|}{ Transfusion rate } \\
\hline Open & 0.77 & 0.84 & 0.28 & 7 & 202 \\
\hline MIS & 0.22 & 0.1 & 0.27 & 4 & 109 \\
\hline Effect: -0.668 & SEM: 0.16 & $95 \% \mathrm{Cl}:-1.04,-0.3$ & $p=0.0028$ & & \\
\hline
\end{tabular}

tion for metopic craniosynostosis allows correction of the evolving fronto-orbital abnormalities much sooner, resulting in excellent long-term outcomes. In addition, we have found MIS to be safe in this very young age group because the surgical time and blood loss are so significantly decreased. The primary underlying principles in treating patients with craniosynostosis using endoscopy-assisted techniques include 1) surgery at an early age; and 2) very rapid brain growth during the 1st year of life. In an attempt to discern the best period for treatment, we decided to operate on children up to 1 year of age. Analysis of our outcomes has led us to determine that the absolute best results are achieved when operating on children who are younger than 3 months of age. However, patients between 3 and 6 months also obtained very good results. Operation at 6-9 months can also provide good outcomes, particularly when compared to traditional calvarial vault remodeling surgeries. We reserve operations in children older than 9 months for when they have a mild deformity and they present with significant irritability and fussiness. We have found that this cohort benefits from surgery by having a marked decrease in irritability and crying and that they still achieve good and acceptable cosmetic outcomes. The use of cranial orthosis after strip craniectomy has allowed continued long-term outstanding cosmetic results.

From a technical standpoint, endoscopic management of stenosed metopic sutures is the most difficult and challenging of all endoscopic procedures performed by our group. There is a significant learning curve, which can be minimized by closely adhering to the surgical principles presented herein. Challenges include the following: a small scalp incision; a relatively long distance from incision to the nasofrontal suture; working in and through a very narrow (5- to 6- $\mathrm{mm}$ ) osteotomy; and presence of a variable number of venous perforators from sagittal sinus to frontal bone in the lower third of the forehead. The use of an endoscopic bipolar is of utmost necessity to deal with the latter problem of vein perforators. However, analysis of our data demonstrates that the EBL was not significantly different or affected by the patient's age, with a median of $25 \mathrm{ml}$ seen across all ages (Fig. 12A). Similarly, surgical time was not affected by the patient's age at the time of surgery, with a median of 57 minutes (Fig. 12B). Open traditional methods of metopic correction certainly still have a role in the treatment of these patients. Patients who have been diagnosed late are often not candidates for strip craniectomy, because the fronto-orbital deformities have become too severe. However, with early evaluation and diagnosis, we have found endoscopy-assisted strip craniectomy to be superior in both cosmetic outcome and surgical performance measures.

The degree and amount of FOA has a significant effect on postoperative frontal sinus development and growth. McCarthy et al. ${ }^{30}$ clearly demonstrated that FOA has an adverse effect on frontal sinus development and forehead aesthetics. A study of 11 patients who underwent bilateral FOA as infants showed that 10 of the patients failed to develop frontal sinuses. ${ }^{33}$ Our procedure does not affect or interfere with the sinuses' progenitor cells and therefore, our patients develop normal sinuses and forehead contours, as demonstrated in Fig. 11. We believe that this presents as another advantage to our surgical approach. 


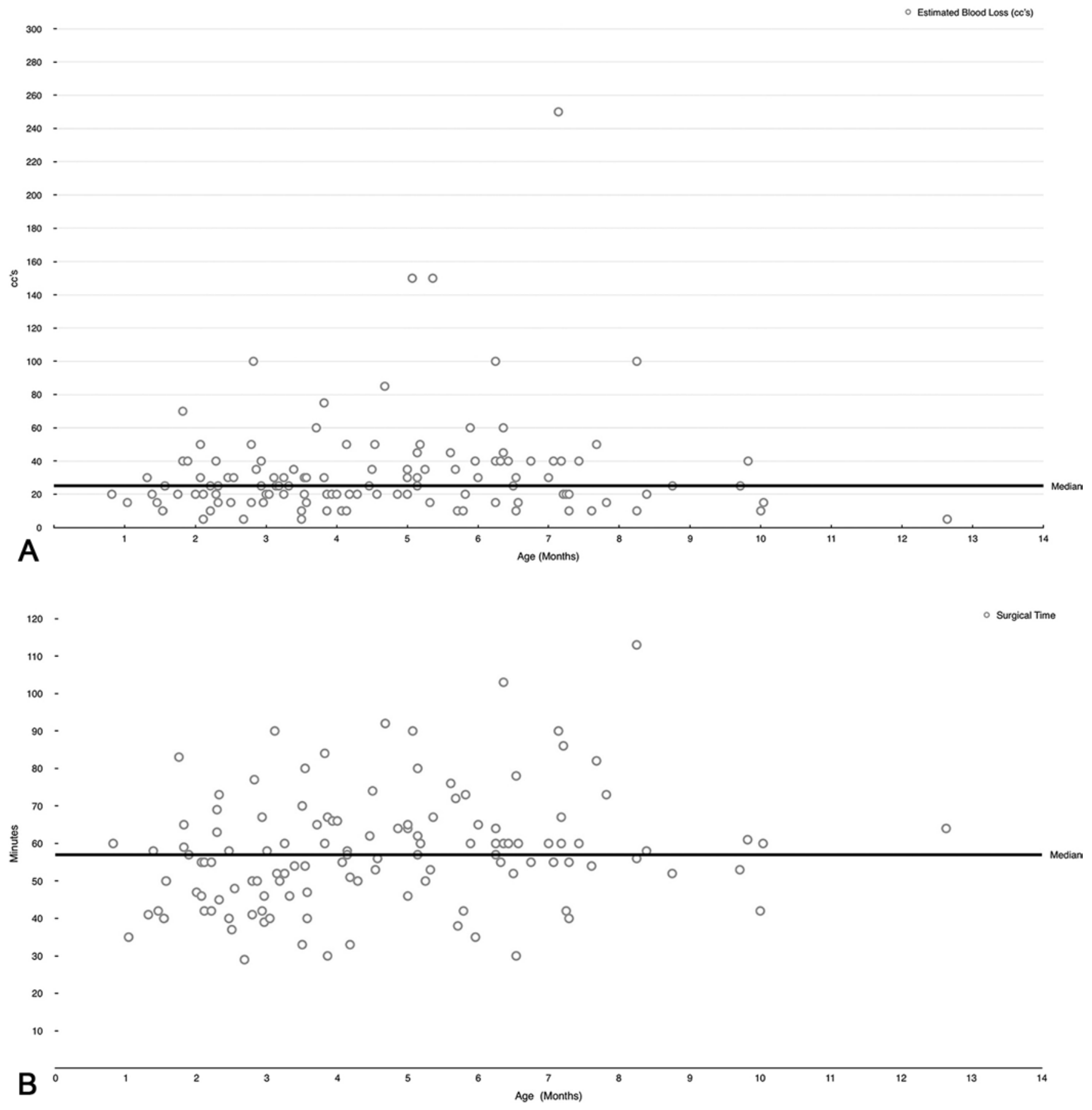

FIG. 12. A: Scatterplot matching patient's age (months) with EBL (milliliters). Data show that blood loss was not affected by patient's age and, except for a few outliers, it was consistent for all ages between 1 and 12 months. B: Scatterplot matching patient's age (months) and surgical time (minutes). Like blood loss, age does not affect surgical time.

\section{Conclusions}

Our experience managing patients with craniosynostosis of the metopic suture during several decades indicates that proper management requires early diagnosis and surgical intervention. The patients who underwent operation at our center all presented with significant frontal defor- mity, and we do not operate on patients who present with late-onset synostosis. This cohort most typically shows a midline prominent metopic suture ridge but a normally rounded forehead and normotelorism. We have demonstrated that early management using minimally invasive resection of the suture, followed by postoperative orthotic 


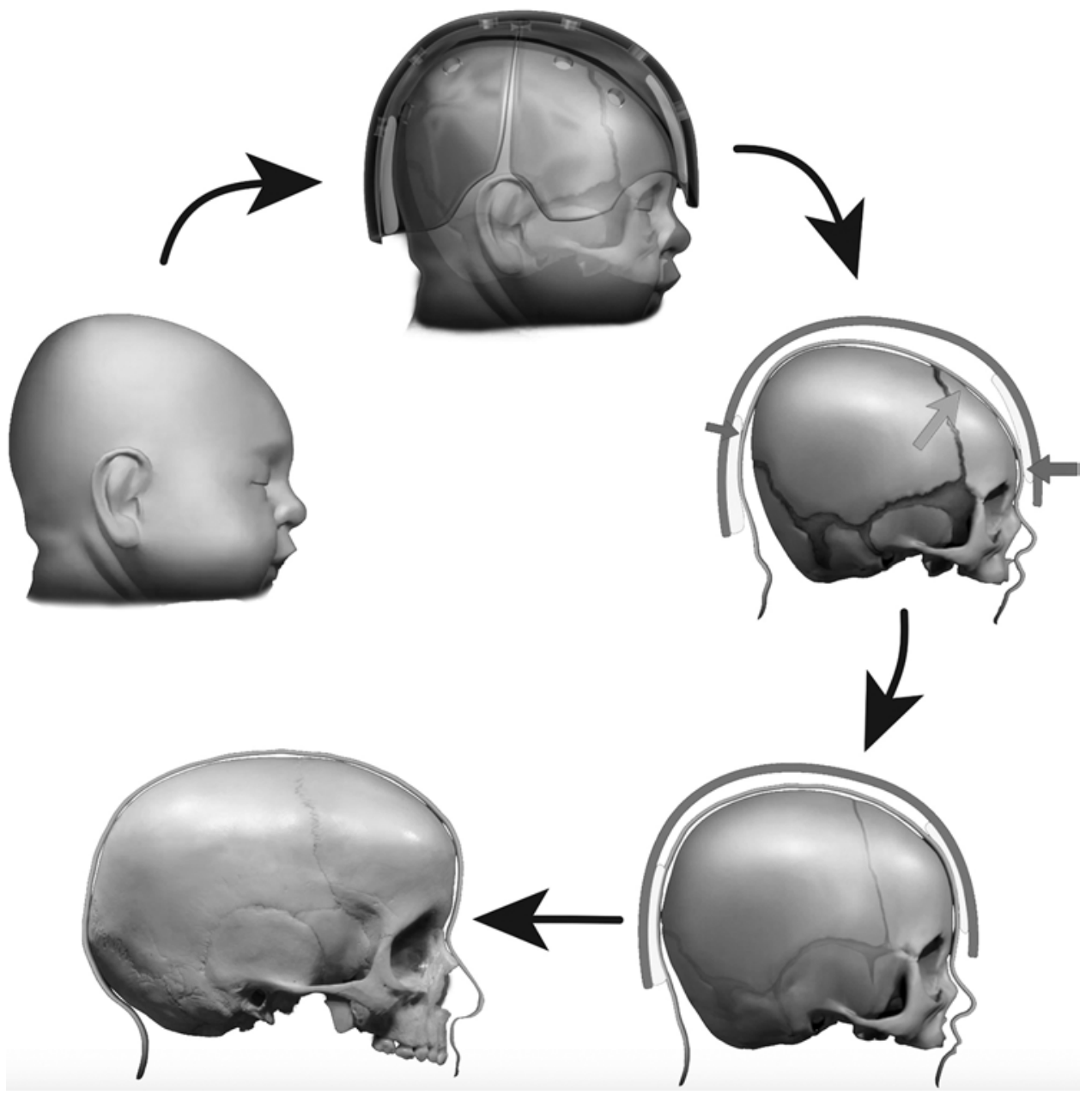

FIG. 13. Image montage depicts the progressive correction and normalization of the cranial vault following early endoscopic metopic suture resection and postoperative orthotic therapy. The effects are lifelong. (c) UTHSCSA. Printed with permission.

therapy, provides the patients with excellent correction and long-lasting results (Fig. 13). This approach should be considered as an option for those patients who are diagnosed early with this clinical condition.

\section{References}

1. Albin RE, Hendee RW Jr, O'Donnell RS, Majure JA: Trigonocephaly: refinements in reconstruction. Experience with 33 patients. Plast Reconstr Surg 76:202-211, 1985

2. Anderson FM: Treatment of coronal and metopic synostosis: 107 cases. Neurosurgery 8:143-149, 1981

3. Aryan HE, Jandial R, Ozgur BM, Hughes SA, Meltzer HS, Park MS, et al: Surgical correction of metopic synostosis. Childs Nerv Syst 21:392-398, 2005

4. Baumgartner JE, Teichgraeber JF, Waller AL, Grantcherova E, Gateno J, Xia JJ: Microscopic approach to craniosynostosis. J Craniofac Surg 16:997-1005, 2005

5. Birgfeld CB, Dufton L, Naumann H, Hopper RA, Gruss JS, Haberkern CM, et al: Safety of open cranial vault surgery for single-suture craniosynostosis: a case for the multidisciplinary team. J Craniofac Surg 26:2052-2058, 2015

6. Breugem CC, van R Zeeman BJ: Retrospective study of nonsyndromic craniosynostosis treated over a 10 -year period. J Craniofac Surg 10:140-143, 1999
7. Britto JA, Gwanmesia I, Leshem D: The Christmas tree foreheadplasty: a novel technique used in combination with a bandeau for fronto-orbital remodelling in craniosynostosis. Childs Nerv Syst 28:1375-1380, 2012

8. Burstein F, Eppley B, Hudgins R, Williams J, Boydston W, Reisner A, et al: Application of the spanning plate concept to frontal orbital advancement: techniques and clinical experience in 60 patients. J Craniofac Surg 17:241-245, 2006

9. Cartwright CC, Jimenez DF, Barone CM, Baker L: Endoscopic strip craniectomy: a minimally invasive treatment for early correction of craniosynostosis. J Neurosci Nurs 35:130-138, 2003

10. Cho BC, Hwang SK, Uhm KI: Distraction osteogenesis of the cranial vault for the treatment of craniofacial synostosis. J Craniofac Surg 15:135-144, 2004

11. Cohen SR, Maher H, Wagner JD, Dauser RC, Newman MH, Muraszko KM: Metopic synostosis: evaluation of aesthetic results. Plast Reconstr Surg 94:759-767, 1994

12. Delashaw JB, Persing JA, Park TS, Jane JA: Surgical approaches for the correction of metopic synostosis. Neurosurgery 19:228-234, 1986

13. Di Rocco C, Velardi F, Ferrario A, Marchese E: Metopic synostosis: in favour of a "simplified" surgical treatment. Childs Nerv Syst 12:654-663, 1996

14. Di Rocco F, Arnaud E, Marchac D, Vergnaud E, Baugnon T, 
Vecchione A, et al: Anterior fronto-orbital remodeling for trigonocephay. Childs Nerv Syst 28:1369-1373, 2012

15. Diluna ML, Steinbacher DM: Simulated fronto-orbital advancement achieves reproducible results in metopic synostosis. J Craniofac Surg 23:e231-e234, 2012

16. Eaton AC, Marsh JL, Pilgram TK: Transfusion requirements for craniosynostosis surgery in infants. Plast Reconstr Surg 95:277-283, 1995

17. Engel M, Thiele OC, Mühling J, Hoffmann J, Freier K, Castrillon-Oberndorfer G, et al: Trigonocephaly: results after surgical correction of nonsyndromatic isolated metopic suture synostosis in 54 cases. J Craniomaxillofac Surg 40:347-353, 2012

18. Erşahin Y: Endoscope-assisted repair of metopic synostosis. Childs Nerv Syst 29:2195-2199, 2013

19. Fearon JA, Ruotolo RA, Kolar JC: Single sutural craniosynostoses: surgical outcomes and long-term growth. Plast Reconstr Surg 123: 635-642, 2009

20. Gociman B, Agko M, Blagg R, Garlick J, Kestle JR, Siddiqi F: Endoscopic-assisted correction of metopic synostosis. J Craniofac Surg 24:763-768, 2013

21. Guzman R, Looby JF, Schendel SA, Edwards MS: Frontoorbital advancement using an en bloc frontal bone craniectomy. Neurosurgery 68 (1 Suppl Operative):68-74, 2011

22. Hinojosa J: Endoscopic-assisted treatment of trigonocephaly. Childs Nerv Syst 28:1381-1387, 2012

23. Hormozi AK, Shahverdiani R, Mohammadi HR, Zali A, Mofrad HRH: Surgical treatment of metopic synostosis. J Craniofac Surg 22:261-265, 2011

24. Jimenez DF, Barone CM: Early treatment of anterior calvarial craniosynostosis using endoscopic-assisted minimally invasive techniques. Childs Nerv Syst 23:1411-1419, 2007

25. Jimenez DF, Barone CM: Early treatment of coronal synostosis with endoscopy-assisted craniectomy and postoperative cranial orthosis therapy: 16-year experience. J Neurosurg Pediatr 12:207-219, 2013

26. Jimenez DF, Barone CM: Multiple-suture nonsyndromic craniosynostosis: early and effective management using endoscopic techniques. J Neurosurg Pediatr 5:223-231, 2010

27. Kelleher MO, Murray DJ, McGillivary A, Kamel MH, Allcutt D, Earley MJ: Non-syndromic trigonocephaly: surgical decision making and long-term cosmetic results. Childs Nerv Syst 23:1285-1289, 2007

28. Keshavarzi S, Hayden MG, Ben-Haim S, Meltzer HS, Cohen SR, Levy ML: Variations of endoscopic and open repair of metopic craniosynostosis. J Craniofac Surg 20:1439-1444, 2009

29. Losken A, Williams JK, Burstein FD, Cohen SR, Hudgins R, Boydston W, et al: Outcome analysis for correction of single suture craniosynostosis using resorbable fixation. J Craniofac Surg 12:451-457, 2001

30. McCarthy JG, Glasberg SB, Cutting CB, Epstein FJ, Grayson $\mathrm{BH}$, Ruff $\mathrm{G}$, et al: Twenty-year experience with early surgery for craniosynostosis: I. Isolated craniofacial synostosis-results and unsolved problems. Plast Reconstr Surg 96:272283, 1995

31. Nguyen DC, Patel KB, Skolnick GB, Naidoo SD, Huang AH, Smyth MD, et al: Are endoscopic and open treatments of metopic synostosis equivalent in treating trigonocephaly and hypotelorism? J Craniofac Surg 26:129-134, 2015
32. Ozlen F, Kafadar AM, Abuzayed B, Ulu MO, Isler C, Dashti $\mathrm{R}$, et al: Surgical treatment of trigonocephaly: technique and long-term results in 48 cases. J Neurosurg Pediatr 7:300310, 2011

33. Paik H, Byeon JH: Anterior two-thirds calvarial remodelling operative technique for the correction of metopic synostosis in toddlers. J Plast Reconstr Aesthet Surg 63:36-41, 2010

34. Patel A, Chang CC, Terner JS, Tuggle CT, Persing JA: Improved correction of supraorbital rim deformity in craniosynostosis by the "tilt" procedure. J Craniofac Surg 23:370-373, 2012

35. Sauerhammer TM, Seruya M, Basci D, Rogers GF, Keating RF, Boyajian MJ, et al: Endocortical plating of the bandeau during fronto-orbital advancement provides safe and effective osseous stabilization. J Craniofac Surg 25:1341-1345, 2014

36. Seruya M, Oh AK, Boyajian MJ, Posnick JC, Myseros JS, Yaun AL, et al: Long-term outcomes of primary craniofacial reconstruction for craniosynostosis: a 12-year experience. Plast Reconstr Surg 127:2397-2406, 2011

37. Shastin D, Peacock S, Guruswamy V, Kapetanstrataki M, Bonthron DT, Bellew M, et al: A proposal for a new classification of complications in craniosynostosis surgery. J Neurosurg Pediatr 19:675-683, 2017

38. Sloan GM, Wells KC, Raffel C, McComb JG: Surgical treatment of craniosynostosis: outcome analysis of 250 consecutive patients. Pediatrics 100:E2, 1997

39. Teichgraeber JF, Baumgartner JE, Waller AL, Reis SM, Stafford MT, Hollinger LE, et al: Microscopic minimally invasive approach to nonsyndromic craniosynostosis. J Craniofac Surg 20:1492-1500, 2009

40. van der Meulen J: Metopic synostosis. Childs Nerv Syst 28:1359-1367, 2012

41. Wes AM, Paliga JT, Goldstein JA, Whitaker LA, Bartlett SP, Taylor JA: An evaluation of complications, revisions, and long-term aesthetic outcomes in nonsyndromic metopic craniosynostosis. Plast Reconstr Surg 133:1453-1464, 2014

\section{Disclosures}

The authors report no conflict of interest concerning the materials or methods used in this study or the findings specified in this paper.

\section{Author Contributions}

Conception and design: Jimenez, Barone. Acquisition of data: all authors. Analysis and interpretation of data: Jimenez, McGinity. Drafting the article: Jimenez, McGinity. Critically revising the article: Jimenez, McGinity. Reviewed submitted version of manuscript: Jimenez, Barone. Approved the final version of the manuscript on behalf of all authors: Jimenez. Statistical analysis: McGinity. Study supervision: Jimenez, Barone.

\section{Correspondence}

David F. Jimenez: UT Health San Antonio, TX. drj@nexusneurosurgery.com. 